\title{
Assessment of Process Parameters by Friction Surfacing on the Double Layer Deposition
}

\author{
Juan Carlos Galvis ${ }^{a *}{ }^{(1)}$, Pedro Henrique Fernandes Oliveira $^{a}{ }^{(0,}$, Juliana de Paula Martins ${ }^{b}$, \\ André Luis Moreira de Carvalho ${ }^{a}$ \\ ${ }^{a}$ Departamento de Engenharia de Materiais, Universidade Estadual de Ponta Grossa - UEPG, Av. \\ Carlos Cavalcanti, 4748, 84030-900, Ponta Grossa, PR, Brasil \\ ${ }^{b}$ Departamento de Engenharia Química, Universidade Tecnológica Federal do Paraná, Av Monteiro \\ Lobato, s/n, km 04, 84016-210, Ponta Grossa, PR, Brasil
}

Received: January 17, 2018; Accepted: February 19, 2018

The friction surfacing process of two deposited layers on two deposition surface conditions, i.e., a smooth interface and a rough interface, was investigated. The control parameter of the deposition process was the rod feed rate with the use of a conventional milling machine. Analyzes of the surface characterization and microstructural characterization along the produced deposits were performed. The interface strength of the substrate/deposit1 (smooth) and deposit1/deposit2 (rough) was evaluated by bending tests and the micro-hardness profile along the transverse section of the substrate/deposit1 and deposit1/deposit2. The bending tests revealed the presence of smalls delaminations with no evidence of fracture at the rough deposit1/deposit2 interface (D1/D2) with less predominance in the deposition condition 3B. This suggests that the combination of the travel speed of $5.5 \mathrm{~mm} / \mathrm{s}$ and an increase in the consumable rod feed rate of $(\geq 5.5 \mathrm{~mm} / \mathrm{s})$ increases the adhesive strength of the two produced interfaces.

Keywords: Friction surfacing, Process parameters, Double Layer, Deposition roughness, Mechanical anchorage, Conventional milling machine.

\section{Introduction}

The continuous development of new technologies and techniques that allow metallic materials to be joined, deposition of material for fabrication of profiles, superficial coating and component recovery, with their characteristics preserved, has been generating great interest in the industrial area in recent years. The search for new alternatives encourages the implementation and incorporation of viable, low cost and reproducible options. The friction surfacing, within these options, is a deposition process that represents an alternative technique for joining and surface coating of similar and/or dissimilar metal components. The process uses heat as the driving force to promote the plastic deformation of a consumable rod on the substrate. Initially, the rod is subjected to a rotational movement with the application of an axial load on the substrate. The heat generated in the friction results in the softening and plastic deformation of the material at the tip of the consumable rod. After plastification occurs, the substrate is subjected to a relative longitudinal movement (advancing) causing the deposition of a layer of the consumable on the substrate. Figure. 1 schematically shows the deposition system and the main process parameters.

Friction Surfacing is a process involving adhesion mechanisms through diffusion that presents great advantages when compared to conventional joining processes (fusion) ${ }^{1}$. One of the great challenges the Friction Surfacing is to improve the degree of adhesion at the edges of the deposits produced in the processing that influences the adhesion quality of the finished products. Therefore, the control of this defect known as cold weld line (undercut) has been studied from the deposition of several deposited layers ${ }^{2}$.

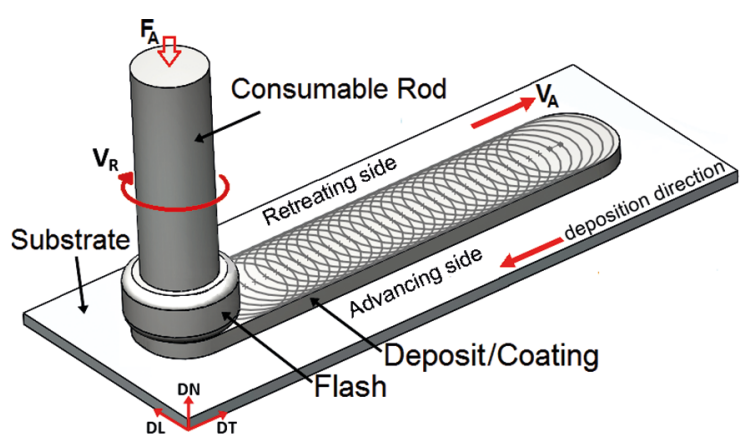

Figure 1. Schematic drawing of the deposition process and process parameters acting on the system

Tokisue et al. ${ }^{3}$ studied the deposition of AA2017 aluminum alloy rods on AA5052 aluminum alloy sheets with double depositions. The process consisted in conducting the second deposition by moving the substrate table at $0,5,10$ and 15 $\mathrm{mm}$ parallel to the first layer deposited on the advancing or indenting sides respectively. The results showed that the deposition of the second layer allowed the decrease 
of unbound edges (cold weld) of the first deposited layer. However, there was no clear effect of the influence of the displacements used in the double deposition on the mechanical properties analyzed in this article. Lambrineas and Jewsbury ${ }^{4}$ investigated different configurations of multiple deposited layers in order to cover surfaces for applications in the maritime industry. The superposition of the deposits was not enough to fully consolidate the joint of the unbound edges of the deposits leaving them empty at the interface between the deposits. Batchelor et al. ${ }^{5}$ studied the deposition of several layers of stainless steel, producing three depositions firmly connected to each other. The depositions were conducted with maintenance of the natural roughness of the deposits. Gandra et al. ${ }^{6}$ developed a study of the wear resistance in an approach based on the deposition of multiple layers by friction surfacing.

It is important to note that even when the cold weld line region decreases with the deposition of several layers, joining the material at the edges cannot be fully consolidated. Consequently, further machining processes to improve the finish and eliminate these defects are necessary. Puli and Janaki $\operatorname{Ram}^{7}$ proposed to machine the unbonded edges by up to $3 \mathrm{~mm}$ ( $1.5 \mathrm{~mm}$ each side) before performing the next deposition. In addition, the deposition of multiple successive layers increases the thickness of the coating surface, thus increasing the possibility of producing profiles with desired geometries after machining processes ${ }^{8}$.

Although studies have been conducted to improve the quality of joining coatings and the reduction of the cold weld regions, few studies have investigated the influence of multilayer deposition on the quality of the joining deposits on the substrate, where the roughness characteristic of the substrates after processing has been maintained between each deposit.

In this context, this article studies two types of interfaces produced in the deposition of two deposited layers with characteristics of smooth and rough joining. That is, in the deposition of the first layer on the substrate, the surface of the substrate is smooth, while in the deposition of the second layer the deposition surface was produced while maintaining the natural roughness of the first layer as a substrate. The main highlight of this article is the emphasis on the deposition characteristics obtained along the rough interface, generated between the two deposited layers, due to the research's process control parameters. Consequently, the aim is to evaluate the microstructure of the deposited material along the two interfaces generated from a microstructural characterization. And, additionally, to evaluate the mechanical behavior of the deposits around the two interfaces through bending tests and hardness profiles. The process was developed using a conventional milling machine where the deposition control was performed by the consumable rod feed rate. The article could contribute in the use of conventional tools, as a viable option for the development of the process, and the advantages that could generate in the industry.

\section{Experimental Details}

The friction surfacing process was performed with 6351 aluminum alloy consumable rods in condition T6 (nominal composition (wt.\%): 98.1Al-0.41Mg-0.86Si$0.42 \mathrm{Mn}-0.072 \mathrm{Cu}-0.19 \mathrm{Fe}-0.003 \mathrm{Cr}$ ) with $19.05 \mathrm{~mm}$ in diameter. Meanwhile, 5052-H32 aluminum alloy sheets (nominal composition (wt.\%): $97.5 \mathrm{Al}-1.87 \mathrm{Mg}-0.086 \mathrm{Si}-$ $0.006 \mathrm{Mn}-0.009 \mathrm{Cu}-0.27 \mathrm{Fe}-0.21 \mathrm{Cr}$ ) of $2.56 \mathrm{~mm}$ thickness were used as substrate. The process parameters were: the travel speed $\left(\mathrm{V}_{\mathrm{A}}\right)$, the rotation speed $\left(\mathrm{V}_{\mathrm{R}}\right)$ which was kept constant for each deposition in a value of $3000 \mathrm{rpm}$. The control parameter used in the processing was the consumable rod feed rate $\left(\mathrm{V}_{\mathrm{z}}\right)$, which is calculated for each deposit as a function of the upward axial displacement of the table (DZ) and the total deposition time $(t)$. The axial force acting on the process is a result of the movement of the table in the upward direction. The deposition rate (DR) and deposition efficiency $\left(E_{f}\right)$ as the process data depending on the rod feed rate were calculated to address the efficiency of the chosen parameters. The control and deposition parameters used in FS processing can be seen in Table 1 . The equipment used in the processing of the consumable material was a KONE KFE-3/BR conventional milling machine equipped with position control in the three axes of the table and fixed head with rotation capacity of $4200 \mathrm{rpm}$. Double layer deposition (one above the other) was performed. As the main highlight of this study, the second layer was deposited on the first layer maintaining the natural roughness resulting from the first deposition, as shown in Figure. 2. The investigative character in this phase was to evaluate the adhesion characteristics of the two layers on the substrate and, mainly, to analyze the effect of the roughness of the first layer on the adhesion of the second deposited layer using as process control the feeding rate of the consumable $\operatorname{rod}\left(\mathrm{V}_{\mathrm{z}}\right)$.

In order to analyze the microstructural and mechanical characteristics of the conducted deposits, for each deposition condition, deposits were obtained by duplicate (XB - XB') as shown in Figure. 3. For microstructural analysis, samples were taken at the beginning, center and end of deposits $1 \mathrm{~B}, 2 \mathrm{~B}$ and $3 \mathrm{~B}$, respectively. The extracted samples were prepared following an electrolytic polishing procedure in an electrolytic solution of $800 \mathrm{~mL}$ of methanol, $60 \mathrm{~mL}$ of $\mathrm{HClO}_{4}$ and $140 \mathrm{~mL}$ of water at $15^{\circ} \mathrm{C}, 3 \mathrm{~A}$ and $30 \mathrm{~V}$ for 60 seconds. Subsequently, they were etched with the Keller reagent (2 $\mathrm{mL} \mathrm{HF}_{48 \%}, 3 \mathrm{~mL} \mathrm{HCl}, 5 \mathrm{~mL} \mathrm{HNO}_{3}$ and $190 \mathrm{~mL}$ of water) followed by the Weck reagent ( $4 \mathrm{~g} \mathrm{KMnO} 4,1 \mathrm{~g} \mathrm{NaOH}$ and $100 \mathrm{~mL}$ of water). Analyzes were performed with an Olympus BX-51 optical microscope. Micro-hardness measurements were performed on the three samples extracted from the central region of the deposits produced from each deposition condition (1B, 2B and 3B) using a LEICA - VMHT MOT hardness tester (load of $200 \mathrm{~g}$ for $15 \mathrm{~s}$ ). Test specimens for three-point bending tests were made from the deposits made from conditions 1B', 2B' and 3B' (duplicates). The tests 
Table 1. Process parameters and control of friction surfacing

\begin{tabular}{|c|c|c|c|c|c|c|}
\hline \multirow[b]{2}{*}{ Experiment } & \multicolumn{6}{|c|}{ Control and deposition parameters used in FS } \\
\hline & $\begin{array}{c}\mathrm{V}_{\mathrm{A}}^{\mathrm{a}} \\
(\mathrm{mm} / \mathbf{s})\end{array}$ & $\begin{array}{c}\mathrm{V}_{\mathrm{R}}^{\mathrm{a}} \\
(\mathbf{r p m})\end{array}$ & $\begin{array}{c}\left(\mathrm{D}_{\mathrm{z}}^{\mathrm{b}} \pm \mathbf{0 . 0 5}\right) \\
\mathbf{m m}\end{array}$ & $\begin{array}{c}\left(\mathrm{t}^{\mathrm{b}} \pm \mathbf{0 . 2}\right) \\
\mathrm{s}\end{array}$ & $\begin{array}{c}\left(\mathrm{V}_{\mathrm{z}}^{\mathrm{c}} \pm \mathbf{0 . 1}\right) \\
\mathbf{m m} / \mathbf{s}\end{array}$ & $\begin{array}{c}\left(\mathrm{DR}^{\mathrm{c}} \pm \mathbf{0 . 0 5}\right) \\
\mathbf{c m}^{3} / \mathrm{min}\end{array}$ \\
\hline $1 \mathrm{~B}-1 \mathrm{~B}^{\prime}$ & 4 & & 61.30 & 12.87 & 4.8 & 90.25 \\
\hline $2 \mathrm{~B}-2 \mathrm{~B}$ & 5 & 3000 & 64.14 & 12.05 & 5.3 & 91.44 \\
\hline $3 B-3 B^{\prime}$ & 5.7 & & 63.04 & 11.45 & 5.5 & 95.76 \\
\hline
\end{tabular}

${ }^{\mathrm{a}}$ Programed; ${ }^{\mathrm{b}}$ Measured; ${ }^{\mathrm{c}}$ Calculated

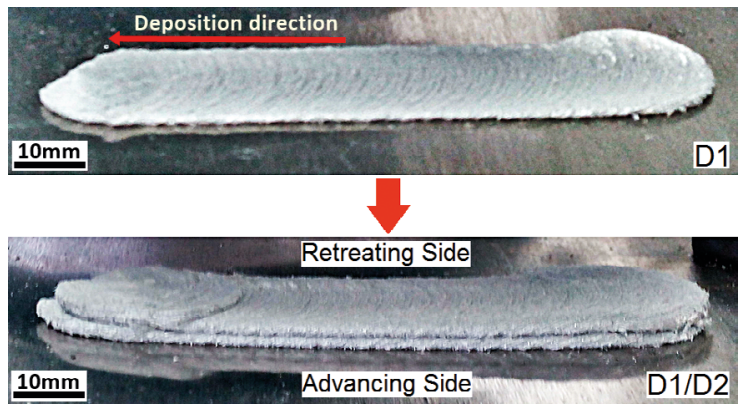

Figure 2. Double-layer deposition sequence maintaining the roughness of the first deposited layer

were performed according to ASTM E-290 in a Shimadzu AG-10 mechanical test machine with a capacity of $10 \mathrm{kN}$ and applied load at $5 \mathrm{~mm} / \mathrm{min}$.

\section{Results and Discussion}

\subsection{Surface characterization of deposits}

Figure 4 shows the transversal macrographs of samples drawn at the center of each of the deposits made under conditions $1 \mathrm{~B}, 2 \mathrm{~B}$ and $3 \mathrm{~B}$, respectively. It is possible to identify a straight line at the substrate/deposit1 interface, which divides the substrate of the deposit (S/D1); whereas in the rough deposit1/deposit2 interface (D1/D2) the two surfaces joined without evidence of the interface. As described above, and contrary to the procedure developed by Dilip and Janaki Ram ${ }^{9}$, the deposition of the second layer was performed maintaining the roughness resulting from the first layer. Thus, double-layer deposits with average thickness of 4.38, 4.30 and $4.33 \mathrm{~mm}( \pm 0.05)$ were obtained. According to Vitanov, Voutchkov and Bedford ${ }^{10}$, the friction surfacing process has a specific feature at the edges of the deposits, known as undercut. This characteristic is influenced by the deposition control of the process, due to the axial force applied or by the consumable rod feed rate. Consequently, the deposition control determines the material flow during the process both in the rotation level (contact between the consumable rod and the top of the deposit) and in the translation level (contact between the substrate and the bottom of the deposit) ${ }^{11,12}$. In this article, from Figure 4, in the deposition process 3B controlled by the consumable rod feed rate of $5.5 \mathrm{~mm} / \mathrm{s}$ (Table 1), there was a significant decrease in the occurrence of undercut at the edges of the deposits, when compared to depositions 1B and 2B. Consequently, this decrease results in increasing the effective width of the two layers deposited on the substrate, as discussed in Figure 5. On the other hand, in Figure 4, the maintained surface roughness of the first deposited layer does not contribute to the decrease of cold welding defects (undercut).

Figure 5 shows the effect of the consumable rod feed rate on the deposition conditions $1 \mathrm{~B}, 2 \mathrm{~B}$ and $3 \mathrm{~B}$ on the length, width, effective width and thickness of the deposits performed. In Figure 5a, it is visible that the length of the deposits increases with increasing travel speed (VA), mainly between 4 and $5 \mathrm{~mm} / \mathrm{s}$. For speeds greater than $5 \mathrm{~mm} / \mathrm{s}$, a slight decrease is observed. In regard to the effective width and width of the deposits, the increase in travel speed and width of the deposits maintains a nearly constant behavior, exhibiting a slight tendency to decrease to a travel speed value

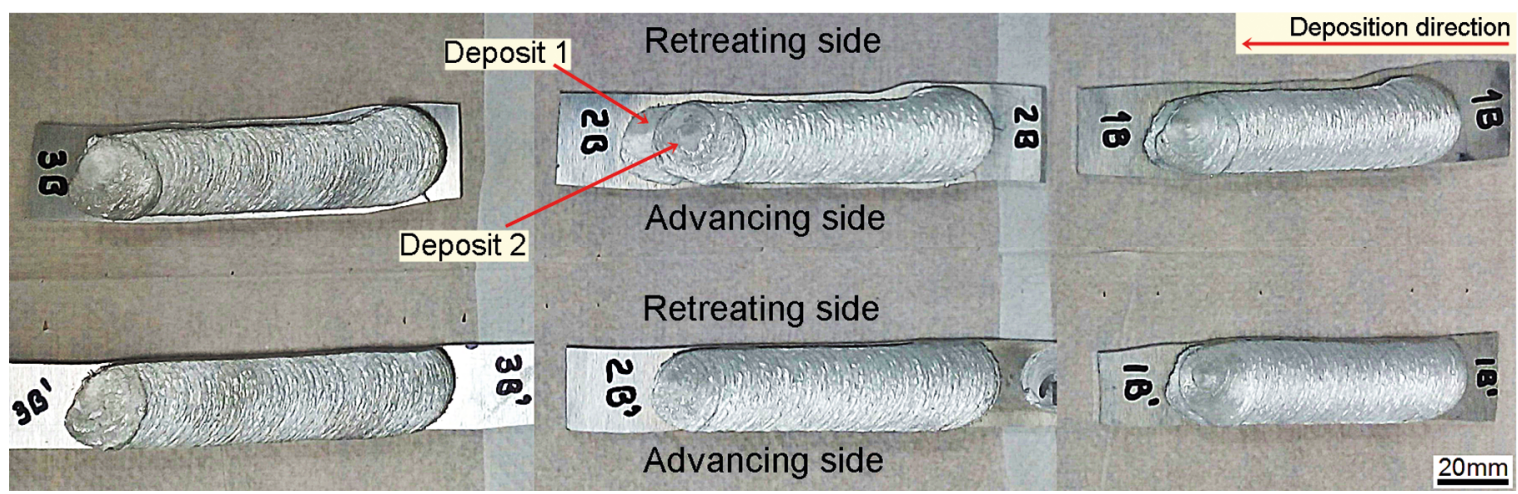

Figure 3. Deposits produced for each deposition condition and its corresponding duplicate 


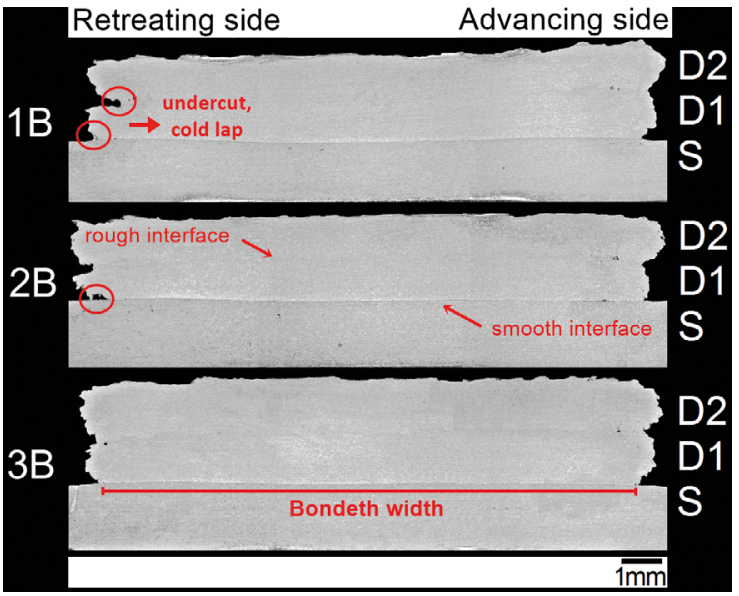

Figure 4. Transversal macrographs of the deposits produced with $\mathrm{V}_{\mathrm{A}}=4,5,5.7 \mathrm{~mm} / \mathrm{s} ; \mathrm{V}_{\mathrm{Z}}=4.8,5.3,5.5 \mathrm{~mm} / \mathrm{s}$ and $\mathrm{V}_{\mathrm{R}}=3000 \mathrm{rpm}$ (deposit conditions $1 \mathrm{~B}, 2 \mathrm{~B}, 3 \mathrm{~B}$ )
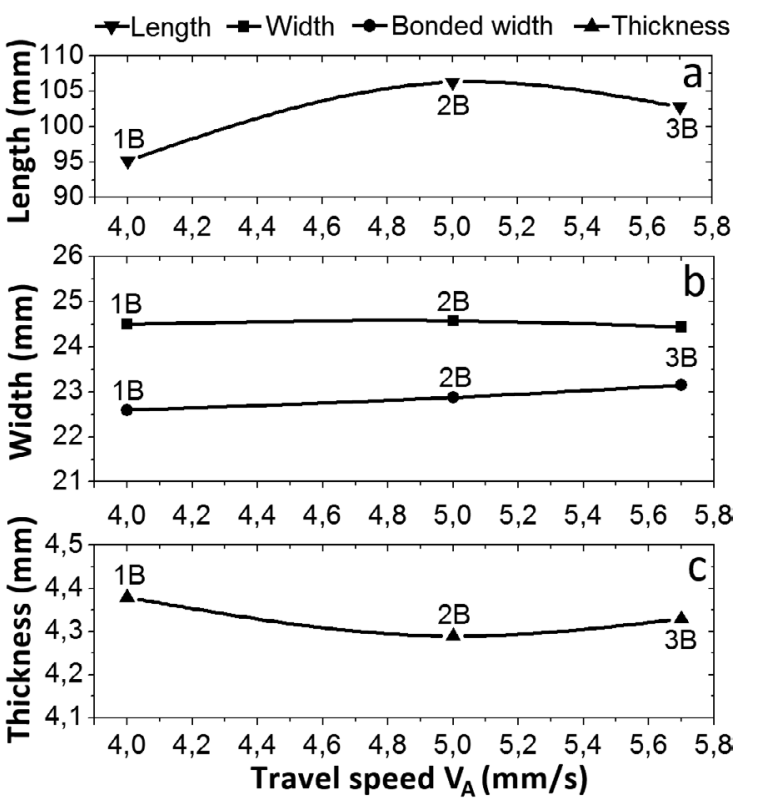

Figure 5. Effect of consumable rod feed rate on: a) Length, b) Width, Effective width and c) Thickness of deposits produced with $\mathrm{V}_{\mathrm{A}}=4$, $5,5.7 \mathrm{~mm} / \mathrm{s} ; \mathrm{V}_{\mathrm{Z}}=4.8,5.3,5.5 \mathrm{~mm} / \mathrm{s}$ and $\mathrm{V}_{\mathrm{R}}=3000 \mathrm{rpm}$ (deposition conditions $1 \mathrm{~B}, 2 \mathrm{~B}, 3 \mathrm{~B})$

of $5.7 \mathrm{~mm} / \mathrm{s}$ as shown in Figure $5 \mathrm{~b}$. However, the effective width, understood as the region of the deposit that is adhered to the substrate (Figure 4$)^{13}$, reveals a gradual increase with increasing consumable rod feed rate (Figure 5b). It is important to clarify that the deposition of consumable rods was performed with three different consumable rod feed rate values (Table 1). As emphasized above, the increase in the consumable rod feed rate $\mathrm{V}_{\mathrm{Z}}$ and the travel speed $\mathrm{V}_{\mathrm{A}}$ results in the increase of the effective width and a decrease of the undercut, as previously described (Figure 4). Normally, when the deposition process is controlled by the applied axial load, the effective width is smaller than the consumable rod diameter $(<3 \mathrm{~mm})$, as reported by Nicholas (1993) and Voutchkov et al. ${ }^{1,14}$. In this article, the deposition process, controlled by the consumable rod feed rate, produced in the smooth interface substrate/deposit1 (S/D1) a 3.5\% increase in the effective width value when compared to the rod used in the processing of the consumable material $(19.05 \mathrm{~mm})$.

On the other hand, in Figure 5c, there is a slight decrease in deposit thickness values with increasing consumable rod feed rate. This behavior may be associated with the increase in the consumable rod feed rate control used to produce the deposits in the $3 \mathrm{~B}$ deposition condition, which was approximately $14.8 \%$ higher when compared to condition $1 \mathrm{~B}$ (Table 1). It is important to emphasize that the increase in rod feed rate induces an increase in the load/pressure acting on the system, resulting in the production of deposits with smaller thickness as reported by Gandra et al. ${ }^{2}$.

\subsection{Consumable rod feed rate}

The consumable rod feed rate, as the control parameter used in the deposition process, is determined by the ratio between the axial displacement of the machine table $\left(\mathrm{D}_{\mathrm{Z}}\right)$ over the total deposition time $t$. It represents the speed at which the rod is consumed along the upward axial displacement of the table relative to the substrate in the friction surfacingprocess. Consequently, the axial load acting on the process is a result of the deposition control used.

Figure 6 shows the evolution of the consumable rods feed rate used to produce the two deposits with deposition condition 2B. In the deposition order, the deposit 1 (black profile) is recorded from the initial rotation of the rod, followed by the contact of the substrate on the consumable (•) and after the deposition. Similarly, deposit 2 (red profile) is recorded from the initial rotation of the rod, followed by contact of the first layer deposited on the consumable $(\bullet \bullet)$ and after the deposition. The total conclusion of the deposition process for each case lasted an approximate time of $20 \mathrm{~s}$.

In deposition of the first layer $(\bullet)$, Figure 6 a shows the instant that the substrate abuts the rod in a time of 4 seconds. In the period between $4-5.8 \mathrm{~s}$ the initial deformation occurs. It was controlled by a rod feed rate of $4.7 \mathrm{~mm} / \mathrm{s}$ (Figure $6 \mathrm{~b}$ ). After the initial deformation occurred, the machine table was subjected to a relative longitudinal movement of $5 \mathrm{~mm} / \mathrm{s}$ in order to make a deposition on the substrate (Figure 6c). At this stage, the deposition process was controlled by a rod feed rate of $5.3 \mathrm{~mm} / \mathrm{s}$, as reported in Table 1 . The linear characteristic of the consumable rod feed rate reveals that the axial load, acting as a consequence of the process, was constant during the processing of the material. A similar result was reported by Gandra et al. ${ }^{15}$. After the consumable rod length reached $64.14 \mathrm{~mm}(\mathrm{t}=16 \mathrm{~s})$ the deposition process was interrupted, as shown in Figure 6d. Similar conditions occurred for deposition of the second layer $(\bullet \bullet)$ as shown in Figure 6. 


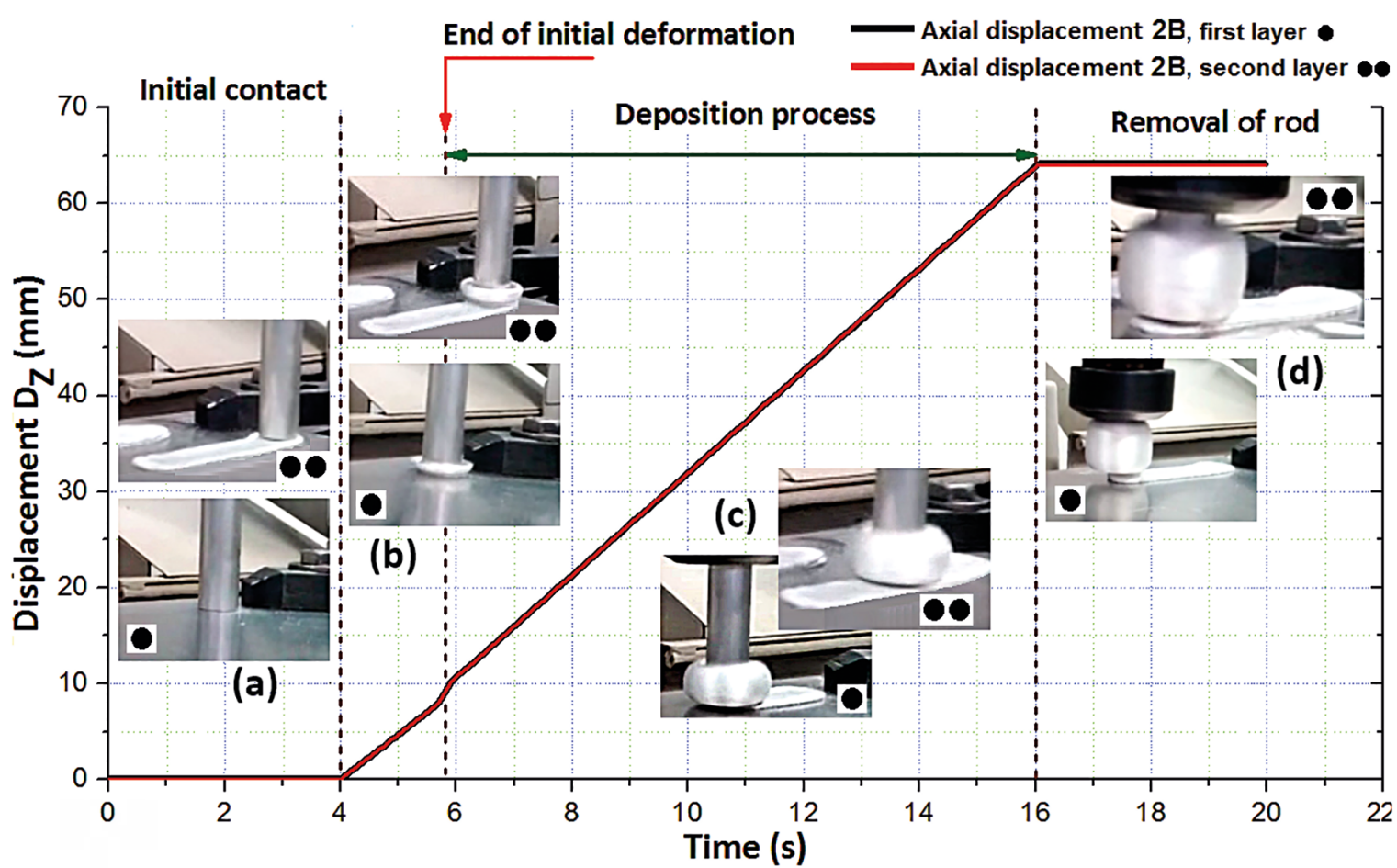

Figure 6. Evaluation of rod feed rate with time in the deposition of double layer AA6351-T6 over AA5052-H32. Initial deformation was controlled by consumable rod feed rate at $4.7 \mathrm{~mm} / \mathrm{s}$. a) Initial contact; b) end of initial deformation; c) deposition process; d) removal of consumable rod. Process parameters for $2 \mathrm{~B}$ condition: $\mathrm{V}_{\mathrm{Z}}=5.3 \mathrm{~mm} / \mathrm{s} ; \mathrm{V}_{\mathrm{A}}=5 \mathrm{~mm} / \mathrm{s} ; \mathrm{V}_{\mathrm{R}}=3000 \mathrm{rpm}$

\subsection{Rate and efficiency of deposition}

The deposition rate (DR), defined as the amount of deposited material per unit time, was calculated from the product between the rod feed rate $\left(\mathrm{V}_{\mathrm{Z}}\right)$ and the transversal area of the two layers deposited on the substrate ${ }^{16}$. Figure 7 a shows the variation of the deposition rate as a function of the rod feed rate used to produce the corresponding deposits under conditions 1B, 2B and 3B, respectively. In Figure $7 \mathrm{a}$, the increase of the rod feed rate results in an increase of the deposition rate (DR) of approximately $5.8 \%$ in the deposition condition 3B, as compared to the condition 1B. Accordingly, increasing travel speed $\left(\mathrm{V}_{\mathrm{A}}\right)$ and the consumable rod feed rate $\left(\mathrm{V}_{\mathrm{z}}\right)$ promotes a decrease in the thickness of the deposit as described in Figure 5c, however, an increase in the effective width of the deposit. Similar results were reported by Gandra et al. ${ }^{13}$. On the other hand, Figure $7 \mathrm{~b}$ shows the variation of the deposition efficiency with the rod feed rate of each of the deposits performed. The deposition efficiency $\left(E_{f}\right)$ represents the relationship between the deposited volume and the consumed volume of the $\operatorname{rod}^{17}$. In this case of double layer deposition, the deposited volume is calculated from the product between the effective width $A e$ of the smooth interface, the thickness $A p$ composed of the two deposited layers and the travel speed $\left(\mathrm{V}_{\mathrm{A}}\right)$ used in each deposition condition, whereas the consumed volume of the rod represents the product between the rod feed rate $\left(\mathrm{V}_{\mathrm{Z}}\right)$ and the consumable (constant) transversal area. As previously described in Figure 5b, increasing the travel speed results in increasing the effective width of the deposits. In turn, the increase of the consumable rod feed rate contributes in decreasing the thickness of the produced deposits. Thus, the effect of these variations between the three conditions analyzed promotes, in the deposition efficiency $E_{f}$, a $10 \%$ increase with regard to the difference between the efficiency values of conditions $1 \mathrm{~B}$ and $3 \mathrm{~B}$, respectively, as shown in Figure $7 b$.

\subsection{Microstructural analysis}

Figure 8 shows the microstructure of the consumable material (AA6351-T6) prior to processing. A morphology of equiaxed grains in the transversal direction DT can be observed in the extrusion process (Figure 8a). Whereas an anisotropic grain structure aligned along the direction of extrusion of the rod is shown in Figure 8b.

During processing, the thermomechanical transformations experienced by the consumable rod lead to a decrease in grain size of the deposited material ${ }^{16,18,19}$. This feature is shown in Figure 9, which shows the transversal micrographs in the center of a deposit in the condition $2 \mathrm{~B}$, obtained in specific regions selected on the retreating side (RS), center region (CR) and advancing side (AS). It is possible to note a fine grain morphology on the retreating (RS) and advancing sides (AS), indicating few variations of grain size between deposited layers (Figure 9a, c, d and f). In the central region, 

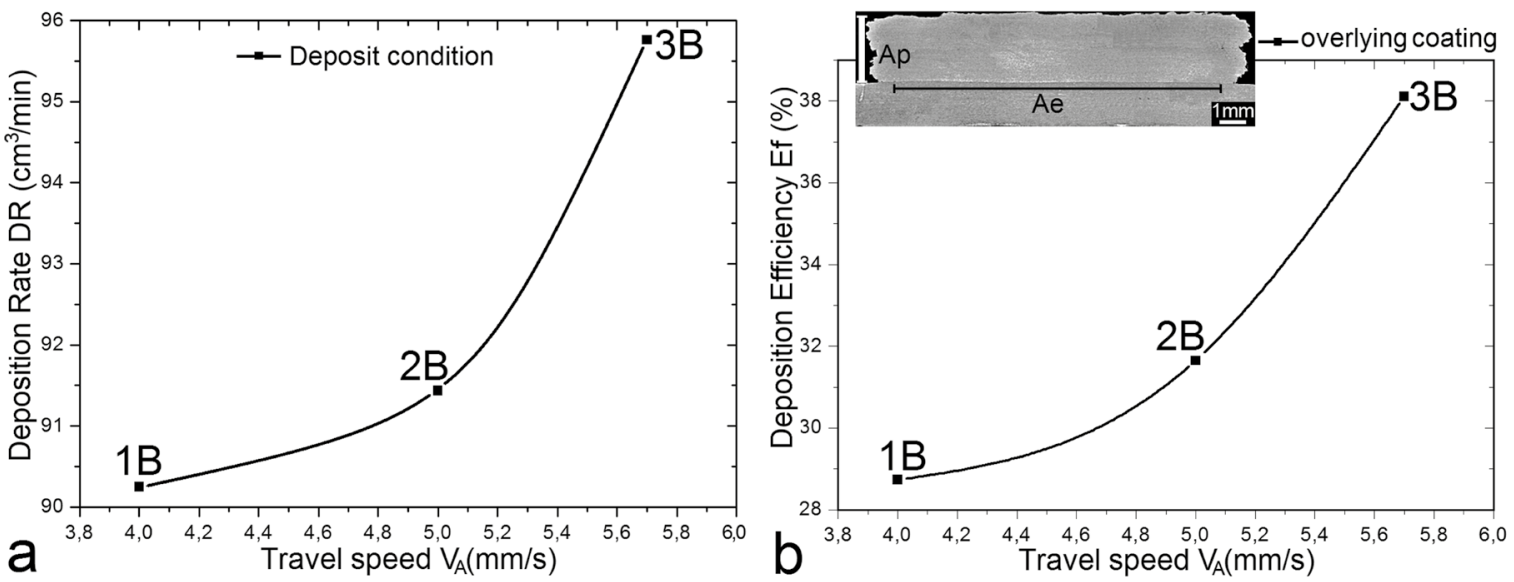

Figure 7. Influence of travel speed on: a) deposition rate $D R$; b) deposition efficiency $E_{f}$
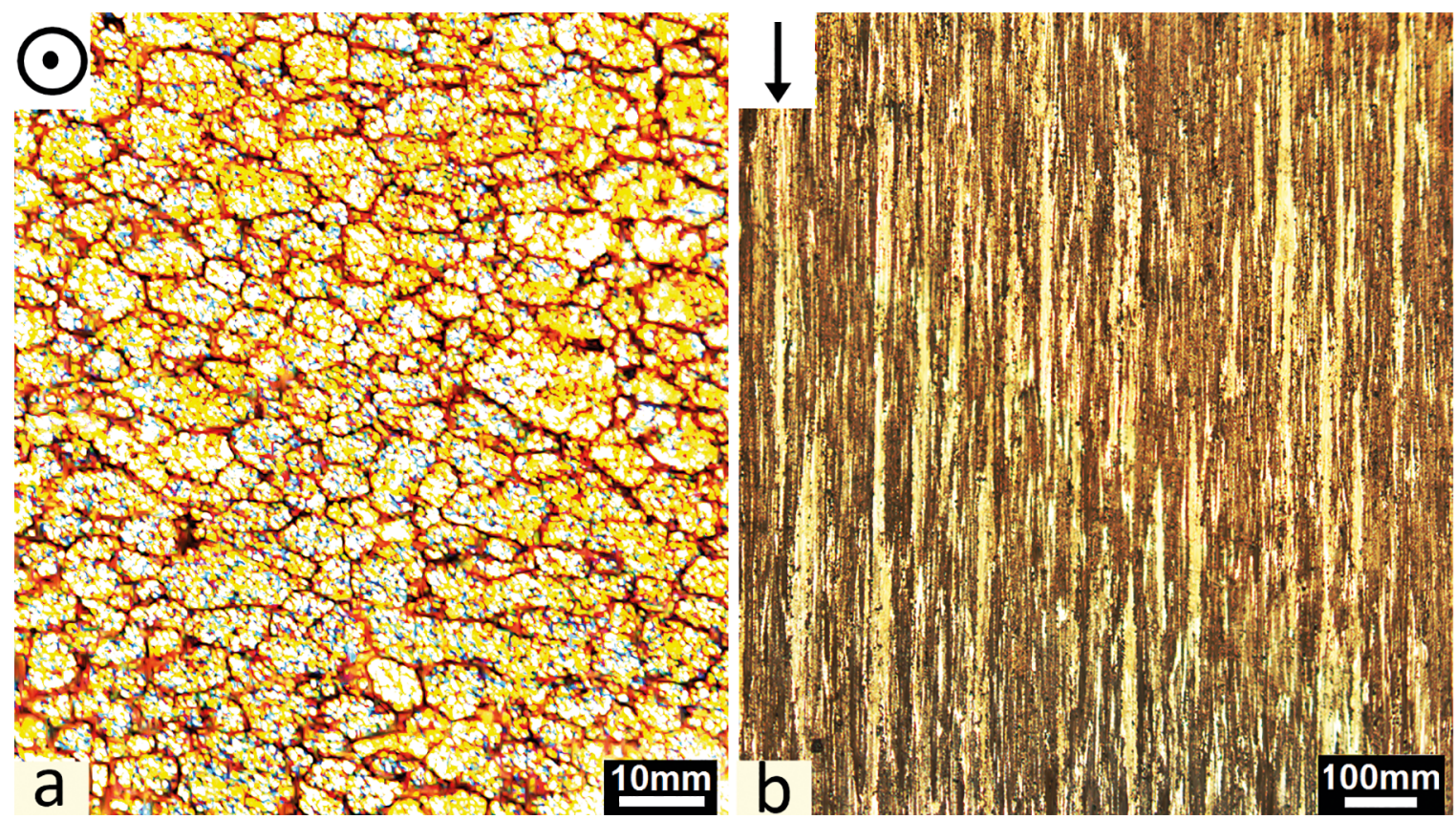

Figure 8. As-received AA6351-T6 consumable rod microstructure: a) perpendicular to rod extrusion direction; b) parallel to rod extrusion direction

Figure $9 \mathrm{~b}$ shows the microstructure of the two deposits along the interface region D1/D2. In this case, the authors noticed a homogeneous section formed by the two layers deposited without evidence of a region that enables the identification of a deposit of the other one, whereas in the substrate/D1 interface region, the presence of a line dividing the two surfaces is shown in Figure 9e.

The micrographs of Figure 10a-c show the microstructure of each deposition condition throughout the deposit1/deposit2 interface region. In micrographs it is possible to observe the presence of a discontinuous line between the deposit interface (D1/D2). As reported by Nicholas and Thomas ${ }^{20}$, in the friction surfacing process the heat generated by the friction between the two surfaces in contact with each other reaches temperatures below the melting temperature of the materials, thus indicating that joining thereof involves diffusion mechanisms. In this article, the interface D1/D2 (Figure 10) also reveals the mechanism of mechanical anchoring, which can be attributed to the roughness of the first layer and favoring joining the materials, as reported by Weiss ${ }^{21}$. On the other hand, this was contrary to what was shown by Dilip and Janaki Ram ${ }^{9}$. It is important to emphasize that the double deposition process was conducted continuously (one after the other), avoiding the presence of impure particles and the formation of oxides on the roughness of the first layer as shown in Figure 11.

\subsection{Vickers Micro-hardness}

Figure 12 describes the hardness profile measured along the central substrate/D1/D2 region for each of the deposits 


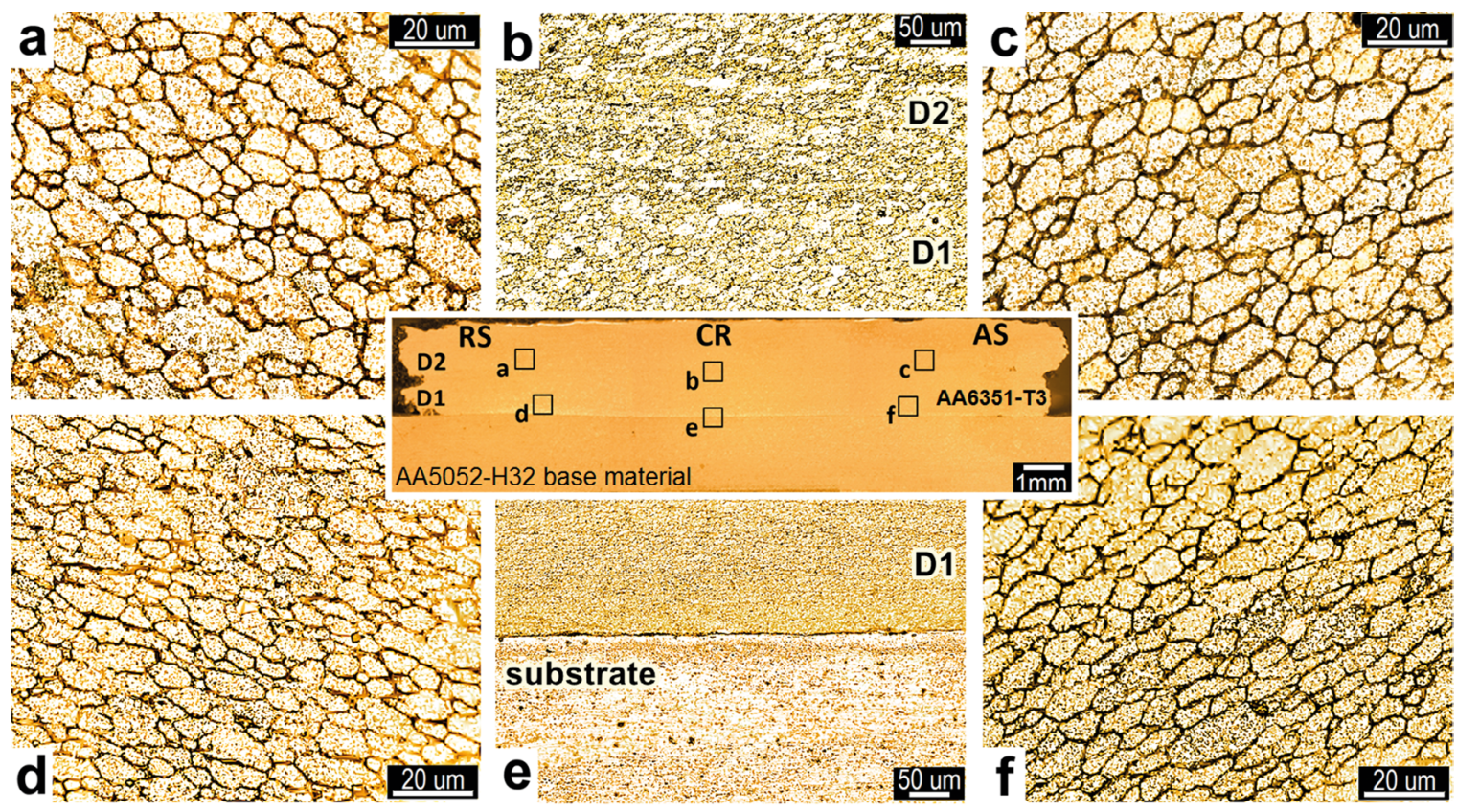

Figure 9. Transversal section with a cut in the center of a double-layer deposit in the deposition condition 2B revealing the microstructure in regions of: a) Retreating side in deposit D2, b) Interface D1/D2, c) Advancing side in deposit D2, d) Retreating side in deposit D1, e) Substrate/deposit interface D2, and f) Advancing side in deposit D1
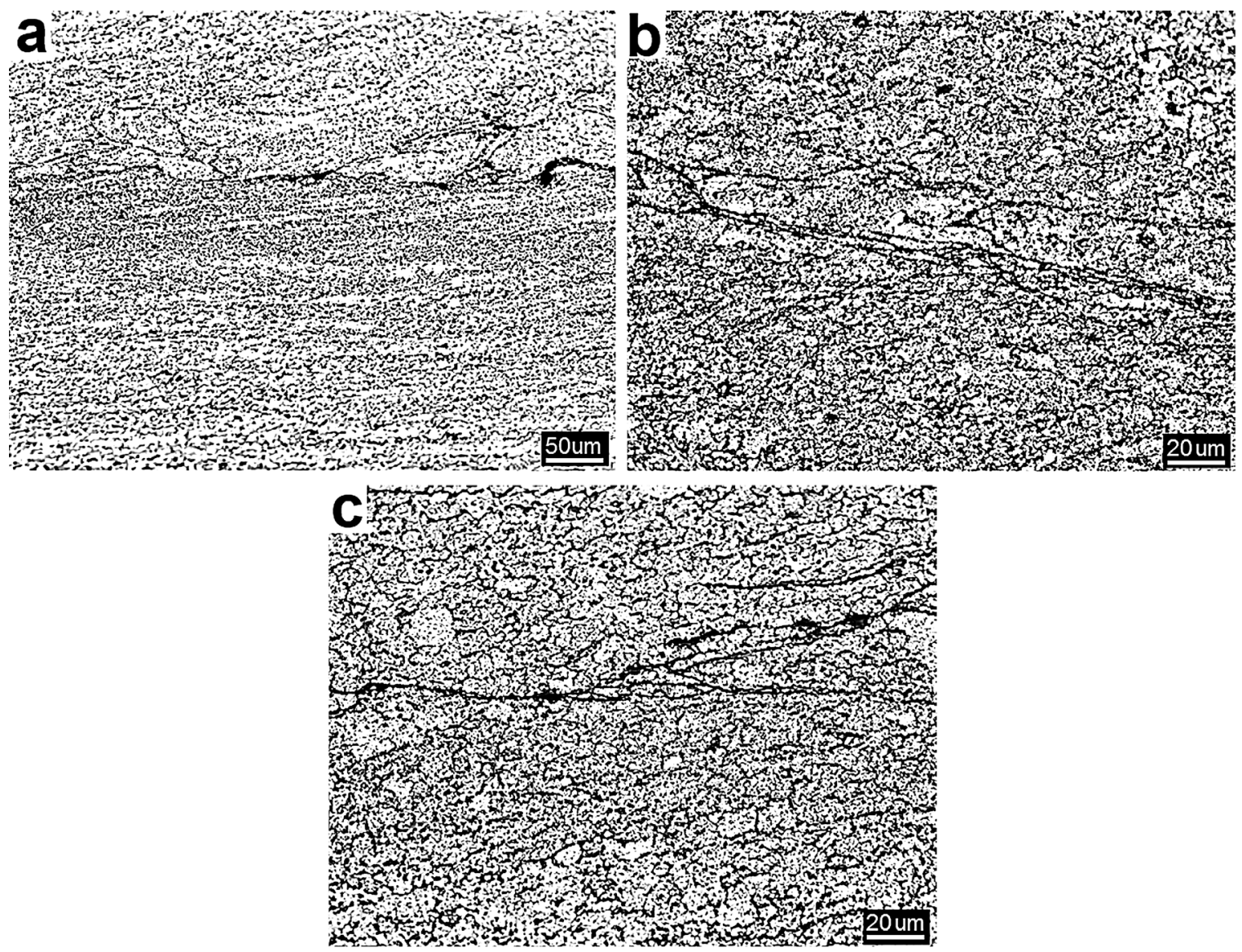

Figure 10. Transversal section along interface deposit1/deposit2 (D1D2) revealing the presence of mechanical anchorage between deposited layers for each deposition condition used: a) 1B, b) $2 \mathrm{~B}$ and c) $3 \mathrm{~B}$ 


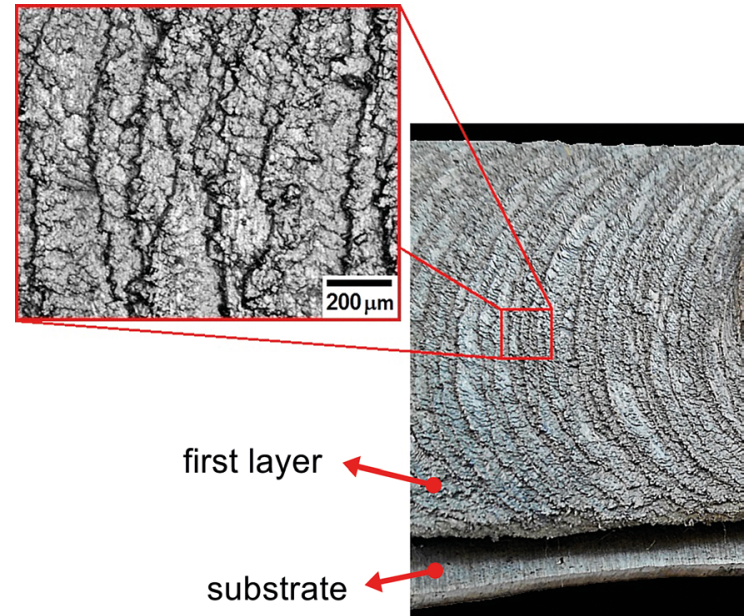

Figure 11. Macrography of the surface roughness of the first layer. Free section of impurities and oxides before deposition process of the second layer

obtained in the three deposition conditions indicated in Table 1. In Figure 12, the hardness values in the substrate decrease to $20 \%, 16 \%$ and $10.4 \%$ (2B, $3 \mathrm{~B}$ and $1 \mathrm{~B}$ respectively) when compared to the hardness values of the substrate (plate AA5052-H32) before processing. This decrease in the hardness values may be associated to the temperature gradient experienced in the substrate during the friction with the consumable rod, whenever the heat-affected zone (HAZ) produced in the substrate is concentrated in the central region, as expected.
Moreover, loss of the T6 condition, along the D1/D2 deposits was around $25.4 \%$, when compared to the hardness of the consumable rod as received. In the deposition region D1/D2, the hardness values show a similar behavior, for the three travel speed conditions used in this study. This result is contrary to the result reported by Gandra et al. ${ }^{6}$. In addition, it is possible to observe in Figure 12 the hardness values along the thickness of the two deposits specifically in the vicinity of interface D1/D2 are similar, indicating that the heat flow produced between the deposited layers (D1/ D2) did not influence the decrease in hardness values. Also hardness values from the transversal section of the double layer measured at the advancing and retreating sides are reported in Table 2. The hardness values are close to the mean values measured at the center of each deposit as expected.

\section{6 Bending test}

An assessment of the adhesion resistance of the deposits on the substrate along the lateral section of the substrate/ deposit1/deposit2 on the retreating and advancing sides is shown in Figure 13. As a result of the bending tests there is evidence of small delaminations at the substrate/deposit1 interface and deposit1/deposit2 with greater predominance at the rough interface deposit1/deposit2, at the retreating side of the deposits obtained with consumable rod feed rate $\left(\mathrm{V}_{\mathrm{Z}}\right)$ of 4.8 and $5.3 \mathrm{~mm} / \mathrm{s}$ and travel speed $\left(\mathrm{V}_{\mathrm{A}}\right)$ of 4 and 5 $\mathrm{mm} / \mathrm{s}$, respectively, as shown in Figure 13a,b. In the case of deposits obtained with consumable rod feed rate of 5.5 $\mathrm{mm} / \mathrm{s}$ and travel speed of $5.7 \mathrm{~mm} / \mathrm{s}$, a reduced delamination

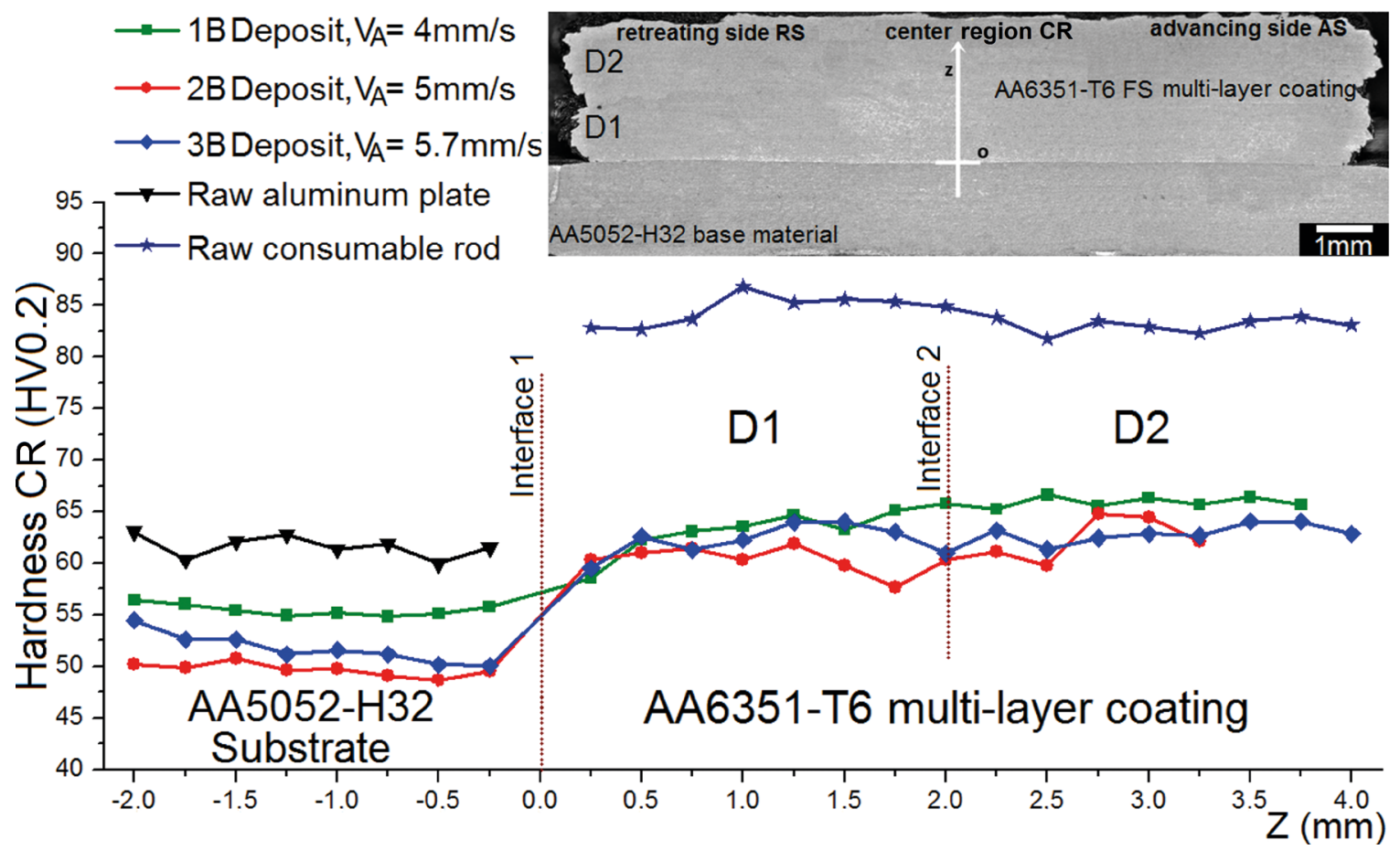

Figure 12. Hardness profile measured along the central region $C R$ of each of the deposits obtained under the used deposition conditions 
Table 2. Average hardness values in double-layer transversal section D1/D2 measured on the retreating side RS, center region CR and advancing side AS of the three deposition conditions.

\begin{tabular}{lccc}
\hline $\begin{array}{l}\text { Deposit condition } \\
\text { (Experiment) }\end{array}$ & \multicolumn{3}{c}{ Microhardness (HV0,2) in cross section D1/D2 } \\
\cline { 2 - 4 } & Retreating Side RS & Center Region CR & Advancing Side AS \\
\hline 1B & 62.73 & 63.51 & 62.74 \\
2B & 60.56 & 61.14 & 60.16 \\
3B & 61.86 & 62.56 & 61.21 \\
\hline
\end{tabular}

Uncertainty value \pm 0.05

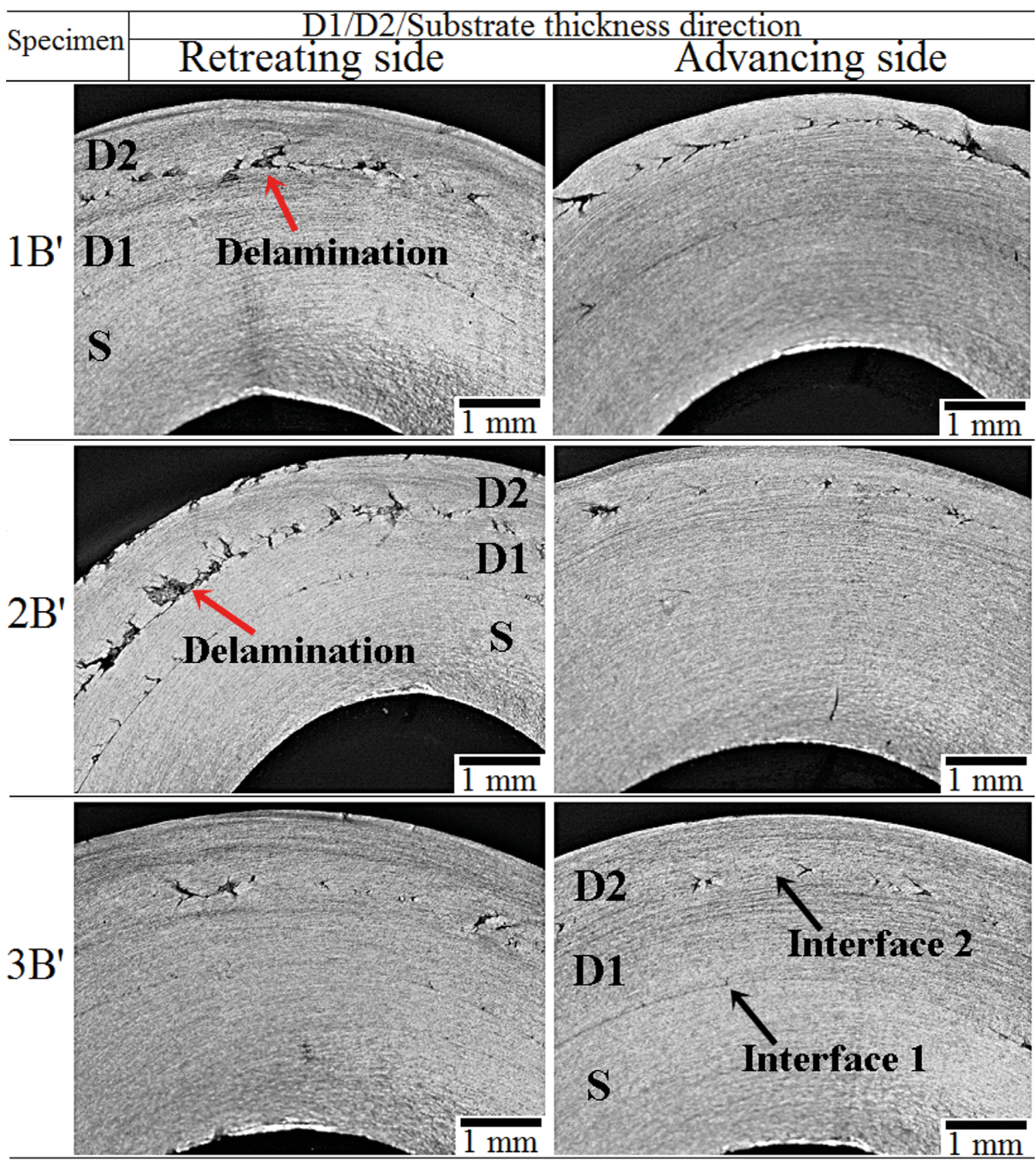

Figure 13. Macrographs of specimens revealing the presence of delamination along the lateral section of the substrate/deposition1/ deposition 2 thickness on the retreating and advancing sides 
presence on both the retreating side and the advancing side along the two interfaces is revealed, Figure $13 \mathrm{c}, \mathrm{f}$. These results show that the higher the consumable rod feed rate of the consumable rod, the greater the axial load applied. Consequently, the proportional increase of the rod feed rate provides more favorable strength/pressure conditions to obtain better adhesion between the two interfaces (S/D1 and D1/D2). It is important to emphasize that in the friction surfacing process, the consumable rod feed rate and applied load are always correlated with each other as reported by Vitanov et al. ${ }^{10}$. Also in Figure 13a-f, with the increasing consumable rod feed rate, the occurrence of delamination along the D1/D2 interface decreases. Similarly, it is possible to note the absence of fracture along the upper bending section as shown in Figure 14.
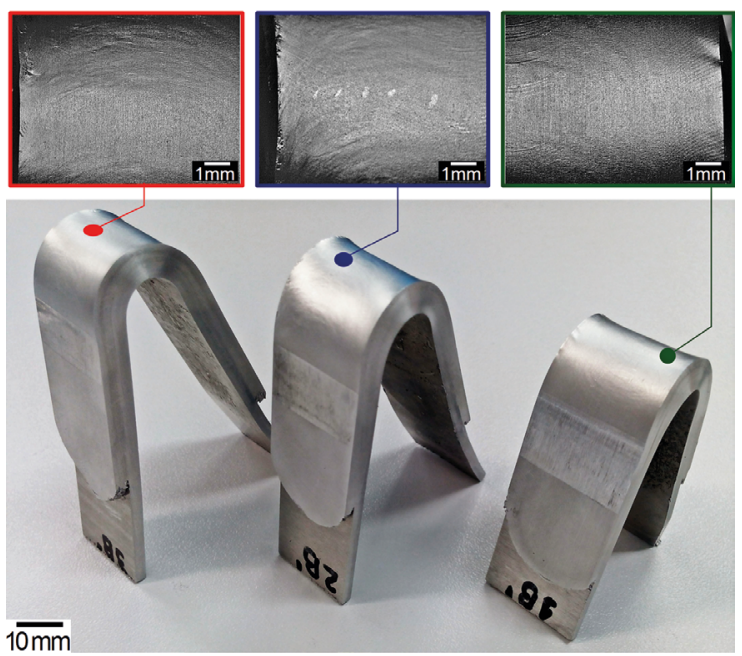

Figure 14. Surface bending section in test specimens without evidence of fracture after testing

\section{Conclusions}

This article evaluated the effect of the roughness of the first deposited layer on adhesion of the second layer using three different rates of consumable rod feed, such as process control. All the surface depositions were conducted through a conventional milling machine, the main results can be thus shown:

- The microstructure of the processed material (AA6351-T6) showed a fine grained morphology on the retreating (RS) and advancing (AS) sides indicating few variations of grain size between deposited layers.

- The consumable rod feed rate of $5.5 \mathrm{~mm} / \mathrm{s}$ significantly decreases the occurrence of undercut at the edges of the deposits, when compared to the other two rod feed rates. In addition, the bonded width of the deposit increases with the increase of the consumable rod feed rate.
- In the interface region D1/D2, the hardness values show a similar behavior for the three investigated conditions. Consequently, the hardness values along the deposits D1/D2 results in the reduction of hardness of $25.4 \%$ when compared to the consumable rod.

- The roughness of the first layer contributes to the mechanical anchoring mechanism occurring along interface D1/D2. However, the maintained surface roughness of the first deposited layer does not contribute to the decrease of cold welding defects (undercut).

- The bending tests revealed the presence of smalls delaminations with no evidence of fracture at the rough interface deposit1/deposit2 (D1/D2) with less predominance in the $3 \mathrm{~B}$ deposition condition. This suggests that the combination of the travel speed of $5.7 \mathrm{~mm} / \mathrm{s}$, and an increase in the consumable rod feed rate $(\geq 5.5 \mathrm{~mm} / \mathrm{s})$ increases the adhesive strength of the two smooth $\mathrm{S} / \mathrm{D} 1$ and rough D1/D2 interfaces produced after processing.

\section{Acknowledgments}

The authors acknowledge Coordination for the Improvement of Higher Education Personnel (CAPES) for the financial support, to National Service for Industrial Training (SENAI) for the opportunity and facilities to use the conventional milling machine and UEPG -State University of Ponta Grossa for the opportunity and facilities from the Multiusers Laboratory Complex C-Labmu. The authors are also grateful the Consortium in R\&D by Friction Processing (C2PA) of number VDT055-12.

\section{References}

1. Nicholas ED. Friction surfacing. In: Olson DL, Siewert TA, Liu S, Edwards GR, eds. ASM Handbook Volume 6: Welding Brazing and Soldering. Materials Park: ASM International; 1993. p. 321-323.

2. Gandra J, Krohn H, Miranda RM, Vilaça P, Quintino L, dos Santos JF. Friction surfacing - A review. Journal of Materials Processing Technology. 2014;214(5):1062-1093. DOI: 10.1016/j. jmatprotec.2013.12.008

3. Tokisue H, Katoh K, Asahina T, Usiyama T. Mechanical Properties of 5052-2017 Dissimilar Aluminum Alloys Deposit by Friction Surfacing. Materials Transactions. 2006;47(3):874-882. DOI: 10.2320/matertrans. 47.874

4. Lambrineas P, Jewsbury P. Areal coverage using friction surfacing. Journal of Ship Production. 1992;8(3):131-136.

5. Batchelor AW, Jana S, Koh CP, Tan CS. The effect of metal type and multi-layering on friction surfacing. Journal of Materials Processing Technology. 1996;57(1-2):172-181. DOI: 10.1016/0924-0136(95)02057-8 
6. Gandra J, Vigarinho P, Pereira D, Miranda RM, Velhinho A, Vilaça P. Wear characterization of functionally graded Al-SiC composite coatings produced by Friction Surfacing. Materials \& Design (1980-2015). 2013;52:373-383. DOI: 10.1016/j. matdes.2013.05.059

7. Puli R, Janaki Ram GD. Microstructures and properties of friction surfaced coatings in AISI 440C martensitic stainless steel. Surface and Coatings Technology. 2012;207:310-318. DOI: 10.1016/j.surfcoat.2012.07.001

8. Vilaça P, Vidal C, Gandra J. Linear friction based processing technologies for aluminum alloys: surfacing, stir welding and stir channeling. In: Ahmad Z, ed. Aluminium Alloys - New Trends in Fabrication and Applications. Rijeka: InTech; 2012. DOI: $10.5772 / 52026$

9. Dilip JJS, Janaki Ram GD. Microstructure evolution in aluminum alloy AA 2014 during multi-layer friction deposition. Materials Characterization. 2013;86:146-151. DOI: 10.1016/j. matchar.2013.10.009

10. Vitanov VI, Voutchkov II, Bedford GM. Decision support system to optimise the Frictec (friction surfacing) process. Journal of Materials Processing Technology. 2000;107(1-3):236-242. DOI: 10.1016/S0924-0136(00)00710-X

11. Fukakusa K. On the characteristics of the rotational contact plane - a fundamental study of friction surfacing. Welding International. 1996;10(7):524-529. DOI: 10.1080/09507119609549043

12. Rafi HK, Phanikumar G, Rao KP. Material Flow Visualization during Friction Surfacing. Metallurgical and Materials Transactions A. 2011;42(4):937-939. DOI: $10.1007 / \mathrm{s} 11661$ 011-0614-2

13. Gandra J, Pereira D, Miranda RM, Vilaça P. Influence of Process Parameters in the Friction Surfacing of AA 6082-T6 over AA 2024-T3. Procedia CIRP. 2013;7:341-346. DOI: 10.1016/j. procir.2013.05.058
14. Voutchkov I, Jaworski B, Vitanov VI, Bedford GM. An integrated approach to friction surfacing process optimisation. Surface and Coatings Technology. 2001;141(1):26-33. DOI: 10.1016/ S0257-8972(01)01127-6

15. Gandra J, Pereira D, Miranda RM, Silva RJC, Vilaça P. Deposition of AA6082-T6 over AA2024-T3 by friction surfacing - Mechanical and wear characterization. Surface and Coatings Technology. 2013;223:32-40. DOI: 10.1016/j.surfcoat.2013.02.023

16. Galvis JC, Oliveira PHF, Hupalo MF, Martins JP, Carvalho ALM. Influence of friction surfacing process parameters to deposit AA6351-T6 over AA5052-H32 using conventional milling machine. Journal of Materials Processing Technology. 2017;245:91-105. DOI: 10.1016/j.jmatprotec.2017.02.016

17. Gandra J, Miranda RM, Vilaça P. Performance analysis of friction surfacing. Journal of Materials Processing Technology. 2012;212(8):1676-1686. DOI: 10.1016/j.jmatprotec.2012.03.013

18. Thomas WM, Nicholas ED, Needham JC, Searle JG. Friction surfacing. Google Patents; 1992.

19. Oliveira PHF, Galvis JC, Martins JP, Carvalho ALM. Application of Friction Surfacing to the Production of Aluminum Coatings Reinforced with $\mathrm{Al}_{2} \mathrm{O}_{3}$ Particles. Materials Research. 2017. In press. DOI: 10.1590/1980-5373-MR-2017-0039

20. Nicholas ED, Thomas WM. A review of friction processes for aerospace applications. International Journal of Materials and Product Technology. 1998;13(1-2):45-55. DOI: 10.1504/ IJMPT.1998.036227

21. Weiss H. Adhesion of advanced overlay coatings: mechanisms and quantitative assessment. Surface and Coatings Technology. 1995;71(2):201-207. DOI: 10.1016/0257-8972(94)01022-B 